Dayasena R.P., Gunarathna C.K.

\title{
Mucormycosis in Otolaryngology - Rhino - cerebral Mucormycosis
}

Dayasena R.P., Gunarathna C.K.

National Hospital of Sri Lanka

\begin{abstract}
Aims

To identify the demography and incidence of the disease, risk factors, early presenting symptoms and signs. Moreover, to recommend early diagnostic methods with effective treatment modalities and to study the possible outcome and complications among the affected patients.
\end{abstract}

\section{Methodology}

This was a prospective study done in histologically confirmed patients affected by the disease, who presented to the ENT department in national hospital Colombo Sri Lanka over one year period.

\section{Results}

There were eleven patients during this one year and it showed $100 \%$ association of Diabetes Mellitus. Almost all the patients had been subjected to surgical debridement in one or many occasions and associated with complications either due to disease or treatments, among the commonest of renal impairment in $47.3 \%$ patients.

\section{Conclusion}

There were significant residual morbidity among survivors and early diagnosis is essential to avoid complication. It is important to increase the awareness about the condition among community and take preventive measures early.

\section{Key words}

Mucormycosis, Diabetes mellitus,

\section{Introduction}

Fungal infections of the nose and paranasal sinuses are increasing in incidence in the community. A number of fungal species has been recognized in the nasal sinus infections. Although in majority of patients the fungus does not invade tissues, a severe form of tissue invasive fungal infections is seen with increasing incidence in the last few years ${ }^{1,3}$. These organisms are classified under 'mucor' and the infection is called mucormycosis. This infection which starts in the nose has a tendency to spread into the sinuses and brain with adverse outcome. Therefore, this condition is commonly refers to as Rhino cerebral mucormycosis ${ }^{2}$.

\section{Methods}

This is a prospective cross-sectional analytical study done over a period of 1 year. The target population was all patients admitted to the National Hospital ENT department under all consultants, who were histologically confirmed of Mucormycosis. Patients who have been previously diagnosed and treated for the same condition were excluded and, their consent obtained verbally. Patient's information was recorded on a well-designed data sheet by the principal investigators or their subordinate medical staff. The treatment was planned according to the currently recommended methods and expert opinions obtained from the Microbiologist, Nephrologist and other relevant specialties. Data analysis was done with SPSS software and recommendations are made based on the results of the study.

\section{Results}

There were eleven patients reported during this period, of which $8(72 \%)$ males and 3 females. The age distribution among affected ones was as follows. 


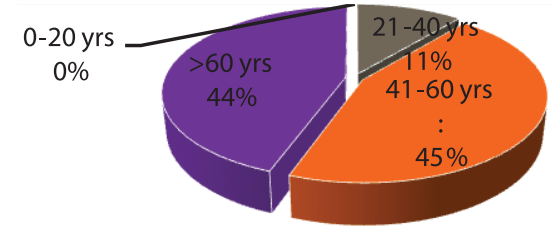

Figure 1.

The Risk factor association.

Table 1

\begin{tabular}{|l|l|l|l|}
\hline & Male & Female & Percentage \\
\hline Diabetes & 8 & 3 & $100 \%$ \\
\hline Metabolic Acidosis & 2 & 0 & $18.1 \%$ \\
\hline HIV & 0 & 0 & 0 \\
\hline Burns & 0 & 0 & 0 \\
\hline Malnutrition & 0 & 0 & 0 \\
\hline
\end{tabular}

The common clinical presenting symptoms and signs were as follows.

\section{Table 2}

\begin{tabular}{|l|l|l|}
\hline Symptoms & No & Percentage \\
\hline Facial Pain & 5 & $45.5 \%$ \\
\hline Headache & 6 & $54.5 \%$ \\
\hline Fever & 4 & $36.4 \%$ \\
\hline Ptosis & 4 & $36.4 \%$ \\
\hline Impaired vision & 5 & $45.4 \%$ \\
\hline Nasal Obstruction & 2 & $18.1 \%$ \\
\hline
\end{tabular}

\section{Table 3}

\begin{tabular}{|c|c|c|}
\hline Sign & $\begin{array}{l}\text { No of } \\
\text { Cases }\end{array}$ & Percentage \\
\hline Temperature & 4 & $36.5 \%$ \\
\hline Impaired Vision & 5 & $45.4 \%$ \\
\hline Diplopia & 3 & $27.27 \%$ \\
\hline Crusting of the nose & 1 & $11.1 \%$ \\
\hline
\end{tabular}

The presence of disease was histologically confirmed in all the patients. Typical finding of necrotic nasal tissue was detected at the $1^{\text {st }} \mathrm{RNE}$ examination only in 4 patients. CT/MRI's opacity found in six and culture positivity was merely in one patient.

Associated comorbidities found among them are as follow in

\section{Table 4}

\begin{tabular}{|l|l|l|}
\hline Co-morbidity & No & Percentage \\
\hline Diabetes & 11 & $100 \%$ \\
\hline Hypertension & 3 & $27.2 \%$ \\
\hline Hyperlipidemia & 2 & $18.2 \%$ \\
\hline Metabolic Acidosis & 2 & $18.2 \%$ \\
\hline IHD & 1 & $11.1 \%$ \\
\hline
\end{tabular}

\begin{tabular}{|l|l|}
\hline Number of Patients & Surgical debridement Times \\
\hline 3 & Once \\
\hline 6 & Twice \\
\hline 2 & Four times \\
\hline
\end{tabular}

\begin{tabular}{|l|c|c|}
\hline Sign & No of Cases & Percentage \\
\hline Temperature & 4 & $36.5 \%$ \\
\hline Impaired Vision & 5 & $45.4 \%$ \\
\hline Diplopia & 3 & $27.27 \%$ \\
\hline Crusting of the nose & 1 & $11.1 \%$ \\
\hline
\end{tabular}

\begin{tabular}{|l|l|l|}
\hline Complications of Treatments & No & $\%$ \\
\hline Renal Impairment & 8 & $72.7 \%$ \\
\hline Liver Dysfunction & 2 & $18.1 \%$ \\
\hline Thrombophlebitis and sepsis & 7 & $63.5 \%$ \\
\hline Other (Hematoma) & 1 & $11.1 \%$ \\
\hline
\end{tabular}

The treatments offered consisted with systemic antifungal treatments (intravenous Amphotericin B) and surgical debridement. Seven patients $(63.5 \%)$ required intravenous antibiotics 
additionally. Surgical debridement had to be Done several times as shown in Table 5. The type of Amphotericin given, was conventional and in 4 patients, it was subsequently shifted to Lipid complex type due to the side effects. The complications related to treatment are depicted in table 6.

Eight patients could completely recover and three patients died mainly due to sepsis.

\section{Discussion}

Mucormycosis is an infection caused by the fungal organisms of the class Phycomycetes. The genes that are commonly recognized to cause human infections include Rhizopus, Absidia, Mucor $^{1,4}$. The human tissues that are commonly infected by these fungi include; Paranasal sinuses, Brain, Lungs, Gastro intestinal tract and skin $^{2}$. These organisms are commonly found in soil, dying plants and bread mold. Also they had been isolated in the nose, throat and stools of normal individuals. Certain conditions especially in which immunity is compromised, it can lead to tissue invasion by the organisms. Some of these conditions include AIDS, Burns, Diabetes (poorly controlled), Leukemia, Metabolic acidosis and Malnutrition ${ }^{3}$.

Organisms can be directly inoculated to the skin wounds and inhaled where they are deposited in the nasal mucosa. They have an affinity to sugar, and acidosis also favors infection. They usually invade the blood vessels, which leads to obliteration of vessels with subsequent necrosis of the tissues.

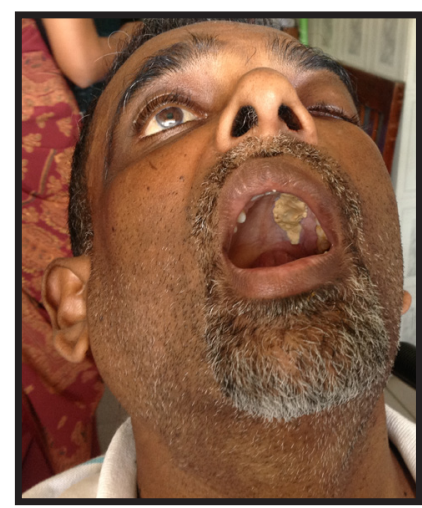

Figure 2. Infected patient with palatal necrosis and orbital involvement.

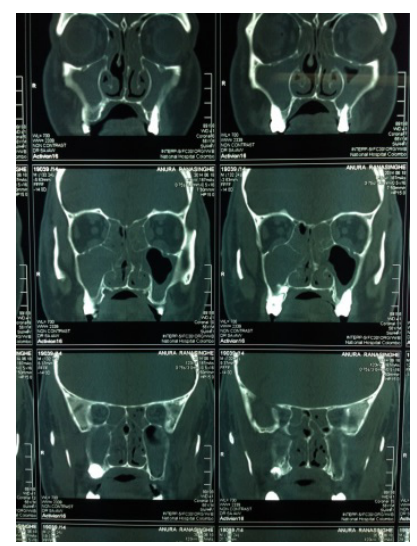

Figure 3. CT imaging of an infected patient

In this series almost all the patients had poorly controlled Diabetes Mellitus. Hence, most of them had already deranged renal functions which was further aggravated by the conventional Amphotericin. However, obtaining renal friendly new formulations (Lipid complex, Lipisomal) which are to be considered as drugs of choice (5), was difficult due to delayed hospital procurement process and the high cost. Peripheral Thrombophlebitis due to Intravenous Amphotericin was averted by insertion of neck and femoral lines. However, this was complicated by line infections and sepsis confirmed by positive blood and tip cultures. This was successfully overcome by the early insertion of PIC lines (peripherally inserted central line) with the help of vascular surgical team. Only three patients showed typical finding of necrotic nasal tissue at the $1^{\text {st }}$ RNE examination, which led to delayed commencement of definitive treatment until histological confirmation. Hence early detection could well be a challenge in some instances and a high index of clinical suspicion is essential.

\section{Conclusion}

The general public and the medical practitioners' awareness regarding the Rhino cerebralMucormycosis should be enhanced, as there will be a possibility of increased incidence of this condition due to increasing prevalence of Diabetes mellitus other immunosuppressive conditions. It is important to take early preventive measures such as stringent blood sugar control. Establishment of early tissue diagnosis would be helpful to avoid delay in treatment. There 
were significant residual morbidity among survivors and early diagnosis is essential to avoid such complications, which could be challenging.

\section{References}

1. Kontoyiannis DP. Mucormycosis. In: Goldman L, Schafer AI, eds. Cecil Medicine. 24th ed. Philadelphia, Pa: Saunders Elsevier; 2011: chap 348.

2. Kontoyiannis DP, Lewis RE. Agents of mucormycosis and entomophthoramycosis.In: Mandell GL, Bennett JE, Dolin R, eds. Principles and Practice of Infectious Diseases. 7th ed. Philadelphia, Pa: Elsevier Churchill Livingstone; 2009: chap 259.

3. Ferguson BJ,Mucormycosis of the nose and paranasal sinuses, OtolaryngolClin North Am. 2000 Apr;33(2):349-65.

4. Odessey E, Cohn A, Beaman K, Schechter L,Invasive mucormycosis of the maxillary sinus: extensive destruction with an indolent presentation, Surg Infect (Larchmt). 2008 Feb; 9(1):91-8. doi: 10.1089/sur.2006.039.

5. Michael.T.Yen, Burke A Cunha, MDhttp://emedicine.medscape.com/ article.

Corresponding Author : Dr. R. P. Dayasena,

Consultant ENT surgeon,

National Hospital of Srilanka.

Email:jdayasena@hotmail.com 